\title{
Heat Sink Device
}

National Cancer Institute

\section{Source}

National Cancer Institute. Heat Sink Device. NCI Thesaurus. Code C49985.

A thermally conductive structure designed to carry heat away from an electronic device. 